\title{
Association between Smoking and Alcohol Consumption and the Severity of Coronary Artery Injuries in Patients with AMI
}

\author{
Luis Gustavo Albuquerque, ${ }^{\circledR}$ Daniel Medeiros Moreira, ${ }^{1,2}{ }^{\circledR}$ Roberto Léo da Silva, ${ }^{2}{ }^{\circledR}$ Tammuz Fattah ${ }^{2 \oplus}$ \\ Universidade do Sul de Santa Catarina (UNISUL),' Palhoça, SC - Brazil \\ Instituto de Cardiologia de Santa Catarina (ICSC), ${ }^{2}$ São José, SC - Brazil
}

\section{Abstract}

Background: Smoking is the most important risk factor for coronary heart disease (CHD) and ischemic events; alcohol consumption, on the other hand, appears to have a protective role.

Objective: Assess the association between smoking and alcohol consumption with the severity of coronary artery injuries in patients with acute myocardial infarction (AMI).

Methods: Cross-sectional study, performed in Santa Catarina. Variables were evaluated using the Chi-squared T/ Fisher's exact test, Kendall's correlation coefficient, Student's t test or Mann-Whitney U test. Values of $\mathrm{p}<0.05$ were considered significant.

Results: Between August 2016 to June 2017, 226 patients were evaluated with first episode of AMI. There was a difference in sex distribution, showing that $59.7 \%$ of men and $85.4 \%$ of women were not alcoholic $(\mathrm{p}<0.001)$. There was a higher prevalence of non-hypertensive patients who consumed alcohol than hypertensive ones $(40.7 \%$ vs. $24.4 \%$ and $\mathrm{p}=0.010)$ and patients without diabetes who had drinking habits than those diabetic $(36.4 \%$ vs. $12.0 \%$ and $\mathrm{p}=0.001)$. There was also a higher prevalence of non-diabetic patients who smoked than diabetic ones $(38.1 \%$ vs. $22.0 \%$ and $\mathrm{p}=0.035)$. A weak and negative correlation was found between the number of cigarettes per day and the pack-year with the TIMI frame count $(r=-0.174$ and $p=0.041$ and $r=-0.192$ and $p=0.027$, respectively). The other associations did not show statistical significance.

Conclusion: The study showed that the number of cigarettes consumed per day and the pack-year is related to a smaller TIMI frame count, i.e., to a better coronary flow, which may be related to the Smoker's Paradox. There was no correlation between the beverage type and quantity with the SYNTAX score, Ejection fraction and TIMI frame count. (Int J Cardiovasc Sci. 2019;32(3)261-268)

Keywords: Coronary Artery Disease Myocardial Infarction, Alcohol Drinking; Tobacco Use Disorder; Risk Factors.

\section{Introduction}

Coronary artery disease (CAD) is the leading cause of morbidity and mortality worldwide. ${ }^{1}$ Every year in Brazil, cardiovascular diseases account for more than one-third of deaths. ${ }^{2}$ CAD is a chronic disease that progresses over a period of years or decades ${ }^{3}$ and results in major social impact. Acute Myocardial Infarction (AMI) is one of the main and often the first manifestation of CAD.

Protective and risk factors for CAD and AMI are widely known in the literature. Several studies indicate that mild-to-moderate alcohol consumption is associated with a 40 to $70 \%$ decreased risk of CAD, compared to no alcohol consumption or heavy alcohol use. ${ }^{4}$ This decreased risk is found in both men and women, ${ }^{5}$ and this protective effect has been observed in various groups. ${ }^{6}$ Smoking, on the other hand, is the most important isolated risk factor - following advanced age - for coronary artery disease. Coronary ischemic events are the cause of death in more than one-third of these patients. ${ }^{7}$ It is undoubtedly the most relevant preventable risk factor of cardiovascular disease. ${ }^{8}$ 
Smoking cessation virtually benefits all smokers, regardless of age, duration or tobacco smoking load. A reduction in mortality rate is observed with smoking cessation at any age. ${ }^{9}$ However, the sooner smoking cessation occurs, the greater the benefits: those who stop smoking by 40 years of age avoid $90 \%$ of the increased risk of death of continuing smoking. ${ }^{10}$

Until this day, tobacco use is clearly present in society, despite numerous efforts of public policies and warnings from the medical community about the harms that smoking causes to a person's health. It is also known that alcohol is toxic for several organs and systems. However, light/moderate and regular alcohol consumption is a protective factor for coronary heart diseases, contributing with reduced AMI risk. In spite of their clear association with cardiovascular morbidity and mortality, there are still gaps concerning the association of these two factors with the severity and complexity of coronary injuries in patients with AMI. Thus, this study aims at assessing the relationship of smoking and alcohol consumption with the severity of coronary injuries in patients with AMI.

\section{Methods}

This was a cross-sectional, observational study carried out in the emergency units of public hospitals in the metropolitan region of Florianopolis, centers of reference in the treatment of patients with AMI, with a population composed by 226 patients seen in the emergency department for AMI, in the period of August 2016 to June 2017. The objectives of this study were to describe the demographic and clinical characteristics of the population; to associate these data with the severity (expressed by the left ventricular ejection fraction - LVEF) and complexity (measured by the SYNTAX score) of coronary injuries and with coronary perfusion after PCI in AMI patients, presenting with ST-segment elevation (assessed by TIMI frame count), and to correlate smoking, alcohol and wine consumption, using the SYNTAX score, LVEF and TFC.

The patients were selected consecutively when admitted to the emergency, diagnosed with first AMI. We included patients over 18 years of age; of both sexes; with precordial pain suggestive of acute myocardial infarction associated with electrocardiogram with new ST segment elevation at the J point in two contiguous leads: $\geq 0.1 \mathrm{mV}$ in all leads, except for leads V2 and $\mathrm{V} 3$, to which the limits of $\geq 0.2 \mathrm{mV}$ in men $\geq 40$ years, $\geq 0.25 \mathrm{mV}$ in men $<40$ years and $\geq 0.15 \mathrm{mV}$ in women are applied, or presence of precordial pain suggestive of acute myocardial infarction associated with elevation in troponin I or CK-MB levels above the $99^{\text {th }}$ percentile of the upper reference limit. Patients with previous acute myocardial infarction were excluded.

This study is an integral part of another ongoing study called Catarina Heart Study, a project entitled "Followup of patients after first acute MI in the state of Santa Catarina: A study of prospective cohort (Catarina Heart Study)", with the general aim of assessing the mortality and severity of ischemic disease in patients with postmyocardial infarction and their potential protective and risk factors. The instrument of data collection used corresponds to that of Catarina Study.

The Catarina Study was submitted and approved by the Committee of Ethics in Human Researches of ICSC (CEP-ICSC), via the Brazil Platform (Plataforma Brasil), and approved with opinion number 1519838.

\section{Statistical analysis}

We calculated a sample of 192 patients to find a mean difference of 2 points in the SYNTAX score, with a standard deviation of 7.0 , power $(80 \%)$, alpha (0.05), among alcohol consumer patients and non-alcohol consumers based on previous data from our group.

The data were tabulated using the Windows Excel software and analyzed using the Statistical Package for the Social Sciences, version 13.0 (SPSS Inc., Chicago, IL, USA, 2005) for Windows. Qualitative data were presented as simple and relative frequencies and assessed using the Chi-square test. Data normality was assessed through the Kolmogorov-Smirnov test. Quantitative data with normal distribution were expressed as mean and standard deviation and assessed using the $t$ test for independent samples. Non-normal quantitative data were described as median and interquartile amplitude and assessed using the Mann-Whitney U test. Correlations were assessed using Kendallıs correlation coefficients, since in all evaluations at least one of the variables presented non-normal distribution. P-values less than 0.05 were considered statistically significant.

\section{Results}

From 2016 to 2017, we analyzed the data of 226 patients who participated of the Catarina Heart Study, admitted to public hospitals of the metropolitan region of Florianopolis, due to AMI. 
The mean age of the patients included in the sample was $59.2 \pm 11.5$ years, $63.7 \%$ male. Of the patients, $59.7 \%$ had SAH, $22.1 \%$ had DM, $35.4 \%$ were dyslipidemic, $42.0 \%$ had a family history of cardiovascular disease and $45.3 \%$ presented with STEMI (Table 1).

With respect to the association between clinical characteristics and alcohol consumption, there was a difference in the distribution by gender: data showed that $59.7 \%$ of men and $85.4 \%$ of women had no alcohol drinking habit $(\mathrm{p}<0.001)$. There was a significantly higher prevalence of patients without hypertension who consumed alcohol (40.7\%) than alcoholic hypertensive patients $(24.4 \%)(\mathrm{p}=0.010)$. Similarly, there was a higher prevalence of patients without diabetes $(36.4 \%)$ than diabetic ones $(12.0 \%)(\mathrm{p}=0.001)$. The other associations did not show any statistical significance (Table 2).

There was a significantly lower prevalence of patients with diabetes who smoked $(22.0 \%)$ than those without diabetes who smoked $(38.1 \%)(\mathrm{p}=0.035)$. The other associations did not show any statistical significance (Table 3).

None of the associations of alcohol consumption and smoking with coronary perfusion after PCI - assessed by the TIMI frame count method - and the severity of the AMI and the complexity of coronary injuries, measured respectively through the LVEF and the SYNTAX score, showed statistical significance (Tables 4 and 5).

A negative and weak correlation was found between the number of pack-year and cigarettes per day with coronary perfusion after PCI - assessed using the TIMI frame count method $(\mathrm{r}=-0.174$ and $\mathrm{p}=0.041$ and $\mathrm{r}=-0.192$ and $\mathrm{p}=0.027$, respectively). The other correlations did not show any statistical significance (Tables 6 and 7).

\section{Discussion}

This is an unprecedented study, which used data from the Catarina Heart Study - a cohort study that has assessed patients admitted to the emergency department of public hospitals in Santa Catarina after a first episode of AMI - and found a negative correlation between variables related to smoking and the TIMI frame count (TFC), that is, to coronary perfusion after PCI.

In relation to the demographic and clinical characteristics, there was a prevalence of male patients with mean age of 59.97 years, similar to the profile of patients seen in other Brazilian hospitals. ${ }^{11,12}$ More

\begin{tabular}{|c|c|c|}
\hline Variables $(n=226)$ & $\mathbf{n}$ & $\%$ \\
\hline \multicolumn{3}{|l|}{ Sex } \\
\hline Male & 144 & 63.7 \\
\hline Female & 82 & 36.3 \\
\hline Age $^{*}$ & $59.2 \pm 11.5$ & \\
\hline Alcohol & 70 & 30.9 \\
\hline Smoking & 78 & 34.5 \\
\hline \multicolumn{3}{|l|}{ SAH† } \\
\hline Yes & 135 & 59.7 \\
\hline No & 91 & 40.3 \\
\hline \multicolumn{3}{|l|}{ DM $\neq$} \\
\hline Yes & 50 & 22.1 \\
\hline No & 176 & 77.9 \\
\hline \multicolumn{3}{|l|}{ Dyslipidemia } \\
\hline Yes & 80 & 35.4 \\
\hline No & 146 & 64.6 \\
\hline \multicolumn{3}{|l|}{ Family History } \\
\hline Yes & 95 & 42.0 \\
\hline No & 131 & 58.0 \\
\hline STEMI§ & 102 & 45.3 \\
\hline NSTEMI I । & 123 & 54.7 \\
\hline \multicolumn{3}{|c|}{$\begin{array}{l}{ }^{*} \text { Mean } \pm \text { standard deviation; }+ \text { Systemic arterial hypertension; } \\
\text { †Diabetes mellitus; §ST-segment elevation myocardial infarction; } \\
\text { | I Non-ST segment elevation myocardial infarction. Source: Author's } \\
\text { elaboration, } 2017 \text {. }\end{array}$} \\
\hline
\end{tabular}

than half of the patients claimed to suffer from SAH, whereas only $22.1 \%$ of patients had DM and $35.4 \%$ had dyslipidemia. Similar data were found by Soares et al., ${ }^{13}$ who showed that the majority of patients had hypertension $(60.3 \%)$, but only $24 \%$ and $35 \%$ had diabetes and dyslipidemia, respectively. ${ }^{13}$ In the current study, less than half of the sample had a family history of cardiovascular disease $(42 \%)$, superior to Brazilian literature data, in which prevalence ranges from 26.8 to $35 \% .{ }^{14,15}$

The results of this study demonstrated no significant difference between the mean SYNTAX score, LVEF and TFC, comparing alcoholic patients with non-alcoholic 


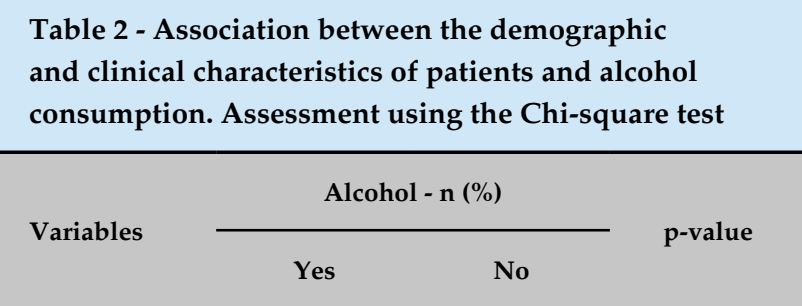

Sex

$\begin{array}{llll}\text { Male } & 58(40.3) & 86(59.7) & <0.001 \\ \text { Female } & 12(14.6) & 70(85.4) & \end{array}$

$\mathrm{SAH}^{*}$

$\begin{array}{llll}\text { Yes } & 33(24.4) & 102(75.6) & 0.010 \\ \text { No } & 37(40.7) & 54(59.3) & \end{array}$

$\mathrm{DM}+$

$\begin{array}{lll}\text { Yes } & 6(12.0) & 44(88.0) \\ \text { No } & 64(36.4) & 112(63.6)\end{array}$

0.001

Dislipidemia

$\begin{array}{lll}\text { Yes } & 20(25.0) & 60(75.0) \\ \text { No } & 50(34.2) & 96(65.8)\end{array}$

Family history

$\begin{array}{lll}\text { Yes } & 32(33.7) & 63(66.3) \\ \text { No } & 38(29.0) & 93(71.0)\end{array}$

*Systemic arterial hypertension; +Diabetes mellitus. Source: Author's elaboration, 2017.

ones. Furthermore, both alcohol and wine intake did not show any correlation with the complexity of injuries and the severity of the infarction - assessed by the SYNTAX score and the LVEF, as well as with the post-infarction coronary perfusion - assessed by the TIMI frame count method. This may indicate that, although alcohol has a protective effect on CAD risk and prevents development of atherosclerosis, ${ }^{16}$ once CAD is established with coronary injuries, alcohol consumption or the amount of alcohol consumed has no effect on the complexity and the severity of injuries in AMI patients. However, the literature lacks studies that determine the correlation of alcohol consumption with the severity and complexity of coronary injuries.

A negative correlation was found between the number of pack-year and the number of cigarettes per day with the TIMI frame count in STEMI patients - that is, with coronary perfusion after PCI. Thus, we can infer that the greater the number of cigarettes smoked or the tobacco

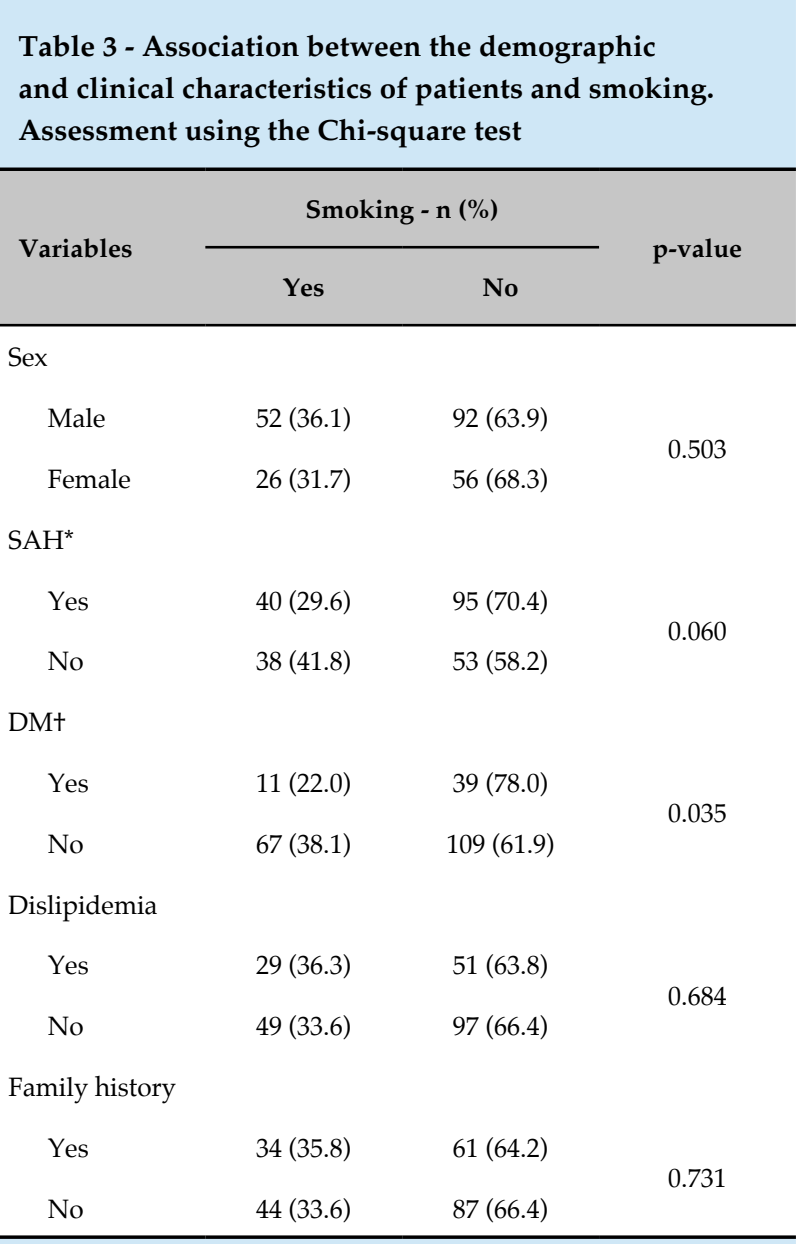

*Systemic arterial hypertension +Diabetes mellitus. Source: Author's elaboration, 2017.

Table 4 - Association of alcohol consumption (g) with the severity of coronary injuries and with ventricular function. Assessment using the independent sample t-test

\begin{tabular}{lccc}
\hline \multirow{2}{*}{ Variables } & \multicolumn{3}{c}{ Alcohol - mean \pm standard deviation } \\
\cline { 2 - 4 } & Yes & No & p-value \\
\hline SYNTAX score & $12.46 \pm 7.85$ & $13.26 \pm 10.72$ & 0.544 \\
LVEF $^{*}$ & $50.41 \pm 11.95$ & $50.24 \pm 15.14$ & 0.947 \\
$\begin{array}{l}\text { TIMI frame } \\
\text { count }+\end{array}$ & $25(14-34)$ & $24(15-36)$ & 0.885 \\
\hline
\end{tabular}

*Left ventricle ejection fraction; +Median (interquartile amplitude). Source: Author's elaboration, 2017.

smoking load, the lower the TFC value and, therefore, the faster the coronary reperfusion after PCI will take place. 


\begin{tabular}{|c|c|c|c|}
\hline \multirow{2}{*}{ Variables } & \multicolumn{3}{|c|}{ Smoking - mean \pm standard deviation } \\
\hline & Yes & No & p-value \\
\hline SYNTAX score & $13.10 \pm 10.02$ & $12.97 \pm 9.89$ & 0.924 \\
\hline LVRF* $^{*}$ & $50.54 \pm 13.61$ & $50.16 \pm 14.67$ & 0.882 \\
\hline $\begin{array}{l}\text { TIMI frame } \\
\text { count }+\end{array}$ & $20(12.5-34)$ & $28(16-36)$ & 0.123 \\
\hline
\end{tabular}

\begin{tabular}{|c|c|c|c|}
\hline Variables & $\begin{array}{c}\text { SYNTAX } \\
\text { score } \\
\text { r (p) }\end{array}$ & $\begin{array}{c}\text { LVEF* }^{*} \\
\text { r (p) }\end{array}$ & $\begin{array}{c}\text { TIMI } \\
\text { frame } \\
\text { count } \\
r(p)\end{array}$ \\
\hline $\begin{array}{l}\text { Years of } \\
\text { smoking }\end{array}$ & $0.010(0.855)$ & $-0.015(0.806)$ & $0.019(0.823)$ \\
\hline Pack-year & $-0.025(0.635)$ & $0.019(0.763)$ & $-0.174(0.041)$ \\
\hline $\begin{array}{l}\text { Cigarettes per } \\
\text { day }\end{array}$ & $-0.029(0.593)$ & $0.017(0.788)$ & $-0.192(0.027)$ \\
\hline
\end{tabular}

\begin{tabular}{|c|c|c|c|}
\hline Variables & $\begin{array}{l}\text { SYNTAX score } \\
\text { r (p) }\end{array}$ & $\begin{array}{l}\text { LVEF* }^{*} \\
\text { r (p) }\end{array}$ & $\begin{array}{c}\text { TIMI frame count } \\
\mathbf{r}(\mathrm{p})\end{array}$ \\
\hline Amount of alcohol consumed (g) & $0.019(0.728)$ & $-0.026(0.683)$ & $0.072(0.404)$ \\
\hline Amount of wine consumed $(\mathrm{g})$ & $0.056(0.325)$ & $-0.095(0.159)$ & $0.030(0.745)$ \\
\hline Amount of alcohol consumed per week ( $\mathrm{g}$ ) & $0.007(0.896)$ & $-0.007(0.912)$ & $0.049(0.562)$ \\
\hline Amount of wine consumed per week (g) & $0.027(0.632)$ & $-0.097(0.154)$ & $0.033(0.725)$ \\
\hline
\end{tabular}

Several data in the literature have found results compatible with the so-called Smoker's Paradox, according to which there is fewer mortality among smoker patients who suffered AMI, in addition to an apparent better coronary perfusion after the use of the thrombolytic therapy or PCI..$^{17,18}$ Such reduction in mortality is attributable to the difference in the profile of patients who suffer an AMI and are smokers: in their vast majority they are younger, since AMI tends to occur up to eleven years earlier among smokers, with fewer associated morbidities - such as DM and SAH - and usually in the inferior wall - associated with lower mortality than anterior wall MI. ${ }^{19,20}$ However, even after adjusting these clinical differences, such paradox persisted, which could be explained by differences in the coronary anatomy and flow patterns in smokers and non-smokers..$^{20-22}$ Angeja et al., ${ }^{19}$ confirmed that smokers demonstrated better epicardial flow than non-smokers, but when they studied microvascular flow measurements, they could not note any differences between these two groups. ${ }^{19}$ A possible explanation for these better results seem to lie in the physiopathological differences between smokers and non-smokers with AMI - due to increased thrombus in smokers - which would induce a greater effectiveness of thrombolytic therapy and a better response to antiplaquetary therapy. ${ }^{23-26}$ However, the literature still lacks studies that quantitatively compare the TFC with the number of cigarettes smoked per day and the number of pack-years of smoking. This finding could thus be explained by the paradoxical effect of smoking on CAD and its association with a better response to post-AMI reperfusion procedures, assuming that smokers may have better myocardial vascularization, in addition to changes at the biochemical physiopathological levels and, therefore, present better TIMI frame count values. We cannot still rule out that this result may also be attributed to chance, given the small proportion of the sample, together with a weak correlation effect. Despite 
the correlation between the number of pack-year and the TFC, there was no association of smoking with the mean SYNTAX score, LVEF and TFC.

The results showed a greater number of alcoholic patients among non-hypertensive than among hypertensive ones ( $40.7 \%$ versus $24.4 \%$ ). Different studies in the literature show that, among hypertensive patients, the majority consumes alcoholic beverages, ${ }^{27,28}$ which diverges from these results. It is known that excessive alcohol consumption is associated with hypertension ${ }^{29}$ and that light-to-moderate alcohol consumption, on the other hand, does not have a substantial impact on blood pressure. ${ }^{30}$ Therefore, we could explain this finding by admitting the possibility that the patients in this study consume less alcohol, which, perhaps, would not be associated with hypertension in the same way as excessive consumption.

The results also show a higher prevalence of nondiabetic patients $(36.4 \%)$ among alcoholic patients than non-diabetic ones $(12.0 \%)$, which may indicate that alcohol has a protective effect on diabetes. Skliros et al also showed that, among patients with light consumption of alcohol, $85.2 \%$ had no DM. ${ }^{27}$ The literature shows that light-to-moderate alcohol consumption is associated with a reduced risk of DM and it seems to play a protective role for its development, ${ }^{31,32}$ which might justify this result.

We also found that most patients who smoked had no diabetes $(38.1 \%)$. On the other hand, studies show that there is an association of smoking with increased DM risk. ${ }^{33,34}$ A possible explanation for this result would be the fact that diabetic patients, already aware of the severity and comorbities associated with their disease, choose to stop smoking. This result may also be attributed to chance.

There was also an association between gender and alcohol consumption, in which $59.7 \%$ of men and $85.4 \%$ of women had no drinking habits $(p<0.001)$. Such difference between sexes was also noted in the Greek study by Skilros et al., ${ }^{27}$ in which $40.2 \%$ of men and $59.8 \%$ of women did not consume alcoholic beverages. ${ }^{27}$

In spite of the careful design and performance of this study, it is worth pointing out that there are some limitations to the analysis and interpretation of the results: it has a cross-sectional design within a cohort that follows patients admitted to emergency departments with a first episode of AMI, and, thus, cannot prove cause/effect. In addition, it has a small sample size, which can be influenced by other variables that were not assessed. Furthermore, the SYNTAX scores found were low, and, therefore, they cannot be extrapolated to a population with higher SYNTAX scores. Certain differences and correlations found can be viewed as the result of mere chance. However, these biases do not invalidate the results found, because it is a study with valuable national data and which raises hypothesis for the development of potential clinical trials and cohorts for the assessment of specific variables, such as smoking and alcohol in AMI. It is worth to highlight that efforts to avoid that patients start smoking or to promote tobacco cessation should be massively employed, and the smoker's paradox should not be mistakenly interpreted and used to encourage cigarette consumption. Moreover, it is necessary to search for a better understanding of the effects of alcohol consumption on the pathogenesis of hypertension and diabetes on a greater number of studies, before encouraging its consumption.

\section{Conclusion}

There was a negative correlation between the number of cigarettes consumed per day and the number of pack-year with the TIMI frame count. There was no correlation between alcohol consumption - be it wine or other types - with the SYNTAX score, the LVEF and the TIMI frame count. The study found an association between alcohol consumption and the prevalence of hypertension, diabetes and patients' sexes. In addition, we found an association of diabetes with smoking. There was no association of the severity and complexity of coronary injuries and ventricular function with smoking and alcohol consumption.

\section{Author contributions}

Conception and design of the research: Albuquerque LG, Moreira DM. Acquisition of data: Albuquerque LG, Silva RL, Fattah T. Analysis and interpretation of the data: Albuquerque LG, Moreira DM. Statistical analysis: Albuquerque LG, Moreira DM. Obtaining financing: Albuquerque LG, Moreira DM. Writing of the manuscript: Albuquerque LG. Critical revision of the manuscript for intellectual content: Albuquerque LG, Moreira DM.

\section{Potential Conflict of Interest}

No potential conflict of interest relevant to this article was reported. 


\section{Sources of Funding}

There were no external funding sources for this study.

\section{Study Association}

This article is part of the thesis of course completion submitted by Luis Gustavo Albuquerque, from Universidade do Sul de Santa Catarina.

\section{Ethics approval and consent to participate}

This study was approved by the Ethics Committee of the Instituto de Cardiologia de Santa Catarina under the protocol number 1.519.838. All the procedures in this study were in accordance with the 1975 Helsinki Declaration, updated in 2013. Informed consent was obtained from all participants included in the study.

\section{References}

1. Moran AE, Forouzanfar MH, Roth GA, Mensah GA, Ezzati M, Murray CJ, et al. Temporal trends in ischemic heart disease mortality in 21 world regions, 1980 to 2010: the Global Burden of Disease 2010 Study. Circulation. 2014;129(14):1483-92

2. Brasil.Ministério da Saúde Secretaria Executiva. Departamento de Informática do DATASUS. Informações de saúde. Morbidade e informações epidemiológicas. Brasília (DF);2010. [citado 2016 nov 16]. Disponível em: www2datasus.gov.br/DATASUS/indexphp?area=0203.

3. Mack M, Gopal A. Epidemiology, traditional and novel risk factors in coronary artery disease. Cardiol Clin. 2014;32(3):323-32.

4. O'Keefe JH, Bybee KA, Lavie CJ. Alcohol and cardiovascular health: the razor-sharp double-edged sword. J Am Coll Cardiol. 2007;50(11):1009-14.

5. Hvidtfeldt UA, Tolstrup JS, Jakobsen MU, Heitmann BL, Grønbaek M, O'Reilly E, et al. Alcohol intake and risk of coronary heart disease in younger, middle-aged, and older adults. Circulation. 2010;121(14):1589-97.

6. Mukamal KJ, Chung H, Jenny NS, Kuller LH, Longstreth WT Jr, Mittleman MA, et al. Alcohol consumption and risk of coronary heart disease in older adults: the Cardiovascular Health Study. J Am Geriatr Soc. 2006;54(1):30-7.

7. Bullen C. Impact of tobacco smoking and smoking cessation on cardiovascular risk and disease. Expert Rev Cardiovasc Ther. 2008;6(6):883-95.

8. Ezzati M, Lopez AD. Regional, disease specific patterns of smokingattributable mortality in 2000. Tob Control. 2004;13(4):388-95.

9. Thun MJ, Carter BD, Feskanich D, Freedman ND, Prentice R, Lopez AD, et al. 50-year trends in smoking-related mortality in the United States. N Engl J Med. 2013;368(4):351-64.

10. Jha P, Ramasundarahettige C, Landsman V, Rostron B, Thun M, Anderson RN, et al. 21st-century hazards of smoking and benefits of cessation in the United States. N Engl J Med. 2013;368(4):341-50.

11. Bacci MR, Fonseca FL, Nogueira LF, Bruniera FR, Ferreira FM, Barros DM, et al. Predominance of STEMI and severity of coronary artery disease in a cohort of patients hospitalized with acute coronary syndrome: a report from ABC Medical School. Rev Assoc Med Bras. 2015;61(3):240-3.

12. Bastos AS, Beccaria LM, Contrin LM, Cesarino CB. Time of arrival of patients with acute myocardial infarction to the emergency department. Rev Bras Cir Cardiovasc. 2012;27(3):411-8.

13. Soares JS, Souza NR, Nogueira Filho J, Cunha CC, Ribeiro GS, Peixoto RS, et al. Treatment of a cohort of patients with acute myocardial infarction and ST-segment elevation. Arq Bras Cardiol. 2009;92(6):430-6.

14. Caluza AC, Barbosa AH, Gonçalves I, Oliveira CA, Matos LN, Zeefried C, et al. ST-elevation myocardial infarction network: systematization in 205 cases reduced clinical events in the public health care system. Arq Bras Cardiol. 2012;99(5):1040-8.

15. Santos ES, Minuzzo L, Pereira MP, Castillo MT, Palácio MA, Ramos $\mathrm{RF}$, et al. Acute coronary syndrome registry at a cardiology emergency center. Arq Bras Cardiol. 2006;87(5):597-602.
16. Femia R, Natali A, L'Abbate A, Ferrannini E. Coronary atherosclerosis and alcohol consumption: angiographic and mortality data. Arterioscler Thromb Vasc Biol. 2006;26(7):1607-12.

17. Kirtane AJ, Martinezclark P, Rahman AM, Ray KK, Karmpaliotis D, Murphy SA, et al. Association of smoking with improved myocardial perfusion and the angiographic characterization of myocardial tissue perfusion after fibrinolytic therapy for ST-segment elevation myocardial infarction. J Am Coll Cardiol. 2005;45(2):321-3.

18. Weisz G, Cox DA, Garcia E, Tcheng JE, Griffin JJ, Guagliumi G, et al Impact of smoking status on outcomes of primary coronary intervention for acute myocardial infarction--the smoker's paradox revisited. Am Heart J. 2005;150(2):358-64.

19. Angeja BG, Kermgard S, Chen MS, McKay M, Murphy SA, Antman EM et al. The smoker's paradox: insights from the angiographic substudies of the TIMI trials. J Thromb Thrombolysis. 2002;13(3):133-9.

20. Barbash GI, Reiner J, White HD, Wilcox RG, Armstrong PW, Sadowsi Z, et al. Evaluation of paradoxic beneficial effects of smoking in patients receiving thrombolytic therapy for acute myocardial infarction: mechanism of the "smoker's paradox" from the GUSTO-I trial, with angiographic insights. Global utilization of streptokinase and tissue-plasminogen activator for occluded coronary arteries. J Am Coll Cardiol. 1995;26(5):1222-9.

21. Grines CL, Topol EJ, O’Neill WW, George BS, Kereiakes D, Phillips HR, et al. Effect of cigarette smoking on outcome after thrombolytic therapy for myocardial infarction. Circulation. 1995;91(2):298-303.

22. Gomez MA, Karagounis LA, Allen A, Anderson JL. Effect of cigarette smoking on coronary patency after thrombolytic therapy for myocardial infarction. TEAM-2 Investigators. Second Multicenter Thrombolytic Trials of Eminase in Acute Myocardial Infarction. Am J Cardiol. 1993;72(5):373-8.

23. Lundergan CF, Reiner JS, McCarthy WF, Coyne KS, Califf RM, Ross AM. Clinical predictors of early infarct-related artery patency following thrombolytic therapy: importance of body weight, smoking history, infarct-related artery and choice of thrombolytic regimen: the GUSTO-I experience. J Am Coll Cardiol. 1998;32(3):641-7.

24. Gurbel PA, Bliden KP, Logan DK, Kereiakes DJ, Lasseter KC, White $A$, et al. The influence of smoking status on the pharmacokinetics and pharmacodynamics of clopidogrel and prasugrel: the paradox study. J Am Coll Cardiol. 2013;62(6):505-12.

25. Ferreiro JL, Bhatt DL, Ueno M, Bauer D, Angiolillo DJ. Impact of smoking on long-term outcomes in patients with atherosclerotic vascular disease treated with aspirin or clopidogrel: insights from the CAPRIE trial (clopidogrel versus aspirin in patients at risk of ischemic events). J Am Coll Cardiol. 2014;63(8):769-77.

26. Gupta T, Kolte D, Khera S, Harikrishnan P, Mujib M, Aronow WS, et al. Smoker's paradox in patients with ST-segment elevation myocardial infarction undergoing primary percutaneous coronary intervention. J Am Heart Assoc. 2016;5(4): e003370.

27. Skliros EA, Papadodima SA, Sotiropoulos A, Xipnitos C, Kollias A Spiliopoulou CA. Relationship between alcohol consumption and control 
of hypertension among elderly Greeks. The Nemea primary care study. Hellenic J Cardiol. 2012;53(1):26-32.

28. Khanal MK, Dhungana RR, Bhandari P, Gurung Y, Paudel KN. Prevalence, associated factors, awareness, treatment, and control of hypertension: findings from a cross sectional study conducted as a part of a community based intervention trial in Surkhet, Mid-western region of Nepal. PLOS ONE. 2017;12(10):e0185806.

29. Sesso HD, Cook NR, Buring JE, Manson JE, Gaziano JM. Alcohol consumption and the risk of hypertension in women and men. Hypertension. 2008;51(4):1080-7.

30. Piano MR. Alcohol's effects on the cardiovascular system. Alcohol Res. 2017;38(2):219-41.
31. Marques-Vidal P, Vollenweider P, Waeber G. Alcohol consumption and incidence of type 2 diabetes. Results from the CoLaus study. Nutr Metab Cardiovasc Dis. 2015;25(1):75-84.

32. Metcalf PA, Scragg RK, Jackson R. Light to moderate alcohol consumption is protective for type 2 diabetes mellitus in normal weight and overweight individuals but not the obese. J Obes. 2014;2014:634587.

33. Willi C, Bodenmann P, Ghali WA, Faris PD, Cornuz J. Active smoking and the risk of type 2 diabetes: a systematic review and meta-analysis. JAMA. 2007;298(22):2654-64.

34. Zhu P, Pan XF, Sheng L, Chen H, Pan A. Cigarette smoking, diabetes, and diabetes complications: call for urgent action. Curr Diab Rep. 2017;17(9):78. 